\title{
Lifetime Poly-Victimization and Posttraumatic Stress Disorder among School- Going Adolescents in Durban, South Africa
}

\author{
Steven J Collings*, Susan L Penning and Sachet R Valjee
}

School of Applied Human Sciences, University of KwaZulu-Natal, Durban, South Africa

*Corresponding author: Steven J Collings, Ph.D., School of Applied Human Sciences, University of KwaZulu-Natal, Durban 4041, South Africa, Tel: 270823004905; Email: collings@ukzn.ac.za

Received date: May 20, 2014, Accepted date: June 26, 2014, published date: July 5, 2014

Copyright: (c) $2014 \mathrm{E}$ du Plessis et al., This is an open-access article distributed under the terms of the Creative Commons Attribution License, which permits unrestricted use, distribution, and reproduction in any medium, provided the original author and source are credited.

\begin{abstract}
In a cross-sectional survey of 719 South African secondary school students, $81 \%$ of respondents reported exposure to two or more types of childhood victimization (poly-victimization), with $29 \%$ qualifying for a diagnosis of posttraumatic stress disorder (PTSD).Risk factors for poly-victimization included poverty, an older age, and type of victimization, with the extent of poly-victimization being highest among respondents who reported an incident of childhood molestation. Respondents exposed to high levels of poly-victimization (5+types) were more than twice as likely as other respondents to qualify for a diagnosis of PTSD $(O R=2.7)$; with there being a graded relationship between the extent of poly-victimization and the severity of PTSD.
\end{abstract}

Keywords: Adolescents; Poly-victimization; PTSD; South Africa

\section{Introduction}

Much of the available literature on childhood victimization has explored the dynamics and impact of single traumatizing events such as sexual abuse, exposure to community violence, school bullying, or witnessing domestic violence[1-4]. Although such studies provide detailed insights into the dynamic of specific forms of exposure, recent literature suggests that childhood victimization frequently involves a pattern of multiple forms of victimization [5-8]. As such, an exclusive focus on one form of victimizations likely to provide only a partial estimate of a child's victimization profile, and, as a consequence, provide a possibly exaggerated estimate of the traumagenic potential of specific types of victimization.

With respect to the notion of multiple victimization, research conducted in the United States indicates that $69 \%$ of children who report any victimization in the past year, report at last one additional, different form of victimization during the same period, and that victimized children report an average of 3 different types of victimization (range: 1-15 types)a year [6]. Finkelhor and his associates refer to such multiple victimization as poly-victimization (PV), with PV having been found to be associated with a variety of adverse behavioral and mental health outcomes, including posttraumatic stress disorder (PTSD) [9,10], suicidal ideation [11], anxiety and depression [6,11-14], risk of future re-victimization $[15,16]$, lower levels of academic performance [11], and delinquent behavior [9].

Although comparative data are not available for developing countries, findings from South African studies indicate that South African adolescents face a high risk of exposure to interpersonal violence, with such exposure being associated with adverse behavioral and mental health outcomes in a significant proportion of cases [17-22]. To date, however, there has been only one systematic attempt to explore the extent of PV in samples of South African adolescents. Using an adapted version of the Juvenile Victimization Questionnaire
[23], McCormack surveyed victimization experiences in a sample of 91, Grade 8 to 10, adolescents in the Cape Province of South Africa. 18 Study findings indicate that respondents reported an average of 6 different types of victimization, with $80 \%$ of respondents falling into the PV category employed in the study (5+ types), and 50\% falling into the high PV category (8+ types).Although McCormack's findings suggest that South African adolescents may be exposed to relatively high rates of $\mathrm{PV}$, the author fails to explore the dynamics and traumagenic potential of such exposure.

In this context, the aims of this exploratory analysis were threefold: first, to explore the extent, dynamics, and traumagenic potential of lifetime PV in a sample of South African school-going adolescents; second, to identify demographic, family background, and victimization characteristics associated with an increased risk of PV; and third, to explore the traumagenic potential of PV using a clinically validated measure of posttraumatic stress disorder.

\section{Methods}

\section{Sample}

The sampling frame for the study was all students attending a high school located in the city of Durban (KwaZulu-Natal, South Africa) during 2011.Of the 802 learners registered at the school, 752 (94\%) consented to participate in the research and 719 (90\%) submitted usable questionnaires. Respondents were predominantly male (66\%) and Black African (95\%), with a mean age of 15.5 years (SD: 2.43, range: $12-20$ years). Additional sample characteristics are provided in Table 1.

\section{Victimisation measures}

Victimization data were collected using the Developmental Trauma Inventory (DTI), which is a 33-item, retrospective, self-administered screen for interpersonal childhood trauma experiences which has been found to have adequate levels of reliability and concurrent validity [24]. The DTI contains probes for nine forms of interpersonal violence 
Page 2 of 5

- emotional abuse, community assault, domestic assault, witnessing community violence, witnessing domestic violence, indecent assault, domestic neglect, rape, and domestic injury -as well as a measure of poverty in the home. In addition, the DTI contains follow-up questions designed to explore: chronicity of exposure, age at first victimization, identity of the perpetrator, and the nature and supportiveness of disclosure.

For purposes of the study a number of measures of PV were created from DTI scores. First, a continuous measure of the total number of lifetime victimizations was obtained by summing the total number of DTI items endorsed. Second, quartile splits were used to provide a graded ordinal ranking of the extent of PV experiences: no PV (0-1 types), low PV (2-4 types), moderate PV (5-8 types), and High PV (9+ types).And third, for some analysis, median splits were used to derive two discrete risk categories: low risk (0-4 types) and high risk (5+types).

\section{Posttraumatic stress measures}

Posttraumatic Stress Disorder was assessed using the Davidson Trauma Scales (DTS), which is a 17-item scale designed to assess for the clinical presence and severity of PTSD symptoms [25] In the present study, Cronbach alphas for DTS scales were: Re-experiencing (.89), Avoidance (.88), Hyper-Arousal (.90), and Full-scale (.95). Following Davidson [24], the severity of symptoms for PTSD subscale scores (Re-experiencing, Avoidance, Hyper-arousal) were calculated by summing frequency and severity scores for each item in the subscale, with full scale severity scores being obtained by summing frequency and severity scores for all 17 items on the scale. With respect to the presence of PTSD, respondents were assumed to meet the criteria for a diagnosis of PTSD if they obtained a minimum frequency score of 2 (2-3 times a week) and a minimum severity score of 2 (somewhat upsetting) for at least: one re-experiencing symptom, 3 avoidance symptoms, and 2 hyper-arousal symptoms.

\begin{tabular}{|c|c|c|c|c|c|}
\hline & & $\begin{array}{l}\text { Extent } \\
\text { victimizat }\end{array}$ & $\begin{array}{l}\text { of poly- } \\
\text { n }\end{array}$ & & \\
\hline Characteristic & $\mathrm{n}$ & $\begin{array}{l}\text { Low risk } \\
\text { (0-4 } \\
\text { types) } \\
(\%)\end{array}$ & $\begin{array}{l}\text { High risk } \\
\left(5^{+}\right. \\
\text {types) } \\
(\%)\end{array}$ & Chi2 (df) & $\mathrm{p}$-value \\
\hline Poverty & & & & $\begin{array}{l}21.06 \\
(1)\end{array}$ & .000 \\
\hline No & 632 & 54 & 46 & & \\
\hline Yes & 87 & 28 & 72 & & \\
\hline Age & & & & $8.57(3)$ & .038 \\
\hline $12-13$ & 96 & 58 & 42 & & \\
\hline $14-15$ & 259 & 53 & 47 & & \\
\hline $16-17$ & 299 & 52 & 48 & & \\
\hline$\geq 18$ & 65 & 35 & 65 & & \\
\hline Grade & & & & $9.93(4)$ & .047 \\
\hline 8 & 150 & 56 & 44 & & \\
\hline 9 & 123 & 58 & 42 & & \\
\hline
\end{tabular}

\begin{tabular}{|c|c|c|c|c|c|}
\hline 10 & 188 & 43 & 57 & & \\
\hline 11 & 154 & 53 & 47 & & \\
\hline 12 & 104 & 48 & 52 & & \\
\hline Gender & & & & $2.92(1)$ & .087 \\
\hline Male & 476 & 49 & 51 & & \\
\hline Female & 243 & 56 & 43 & & \\
\hline Caretakers & & & & $0.73(2)$ & .695 \\
\hline Both parents & 345 & 50 & 50 & & \\
\hline One parent & 252 & 52 & 48 & & \\
\hline Guardian/other & 122 & 54 & 46 & & \\
\hline Ethnicity & & & & $0.16(1)$ & .724 \\
\hline Black African & 684 & 51 & 49 & & \\
\hline Other & 35 & 55 & 45 & & \\
\hline
\end{tabular}

Table 1: Demographic characteristics and extent of poly-victimization $(\mathrm{n}=719)$

\section{Procedure}

Ethical clearance for the research was obtained from the Humanities Ethics Committee at the University of KwaZulu-Natal, with parental consent, and respondent assent, being obtained from all participants. Research questionnaires were administered by the researchers to groups of consenting participants during Life Orientation lessons; with offers of free counseling support (from the school guidance teacher) and/or free psychological counseling/therapy (at a University Clinic) being made to all respondents.

\section{Results}

\section{Prevalence of PTSD}

Two hundred and twelve respondents (29.5\%) met the DTS criteria for a diagnosis of PTSD, with PTSD outcomes being significantly more likely among female respondents $(\mathrm{OR}=2.2,95 \% \mathrm{CI}=1.6-3.1)$ and among respondents who reported poverty in the home $(\mathrm{OR}=2.7,95 \%$ $\mathrm{CI}=1.7-4.2)$.

\section{Extent of poly-victimisation}

Six-hundred and forty-eight respondents (90\%) reported life-time exposure to at least one form of victimization, with $90 \%$ of those who reported at least one type of victimization reporting one or more additional form of victimization. The median number of types of exposure reported by victimised respondents was 5(range: 1 to 24), with $36 \%$ of victimized respondents reporting low PV (2-4 types), 32\% reporting moderate PV (5-8 types), and 22\% reporting high PV (9+ types).

\section{Risk of poly-victimisation}

The risk of $\mathrm{PV}$ varied as a function of both respondent characteristics and type of victimization. High levels of PV (5+types) were significantly more likely to be reported by: respondents who grew 
up in a home characterized by poverty, by older respondents, and by respondents in higher grades; with respondent's gender, ethnicity, and family structure being unrelated to risk of PV (Table 1).

The risk of PV also varied as a function of the type of victimization (Table 2). Respondents who reported the following types of victimization all had more than $80 \%$ of their members in the high risk PV category (i.e., 9+ types of victimization): molestation, domestic injury, neglect, rape, and emotional abuse.

\begin{tabular}{|l|l|l|l|l|}
\hline \multirow{2}{*}{ Type of victimization } & $\mathbf{n}$ & \multicolumn{2}{|l|}{ Poly-victimization (\%) } & $\begin{array}{l}\text { Mean } \\
\text { number } \\
\text { of types }\end{array}$ \\
\cline { 3 - 5 } & & $\begin{array}{l}\text { Low risk } \\
\text { (0-4 types) }\end{array}$ & $\begin{array}{l}\text { High risk } \\
\text { (5+ types) }\end{array}$ & \\
\hline Any molestation & 446 & 13 & 87 & 12.0 \\
\hline Any domestic injury & 43 & 14 & 86 & 10.7 \\
\hline Any rape & 43 & 20 & 80 & 9.5 \\
\hline Any emotional abuse & 187 & 20 & 80 & 9.4 \\
\hline $\begin{array}{l}\text { Any witness } \\
\text { (domestic) }\end{array}$ & 230 & 22 & 78 & 8.8 \\
\hline $\begin{array}{l}\text { Any community } \\
\text { assault }\end{array}$ & 288 & 26 & 74 & 8.0 \\
\hline Any domestic assault & 352 & 27 & 73 & 7.8 \\
\hline $\begin{array}{l}\text { Any witness } \\
\text { (community) }\end{array}$ & 446 & 32 & 68 & 7.1 \\
\hline
\end{tabular}

Table 2: Extent of poly-victimization by type of victimization $(n=719)$

\section{Relationship between poly-victimisation and PTSD}

Poly-victimization was strongly predictive of PTSD with respondents who reported high levels of PV (5+ types) being more than twice as likely as other respondents to meet the criteria for a diagnosis of PTSD (OR=2.72, 95\% CI=1.903.8).A more fine-grained analysis of the relationship between PV and PTSD was provided by an exploration of the relationship between PV and PTSD severity scores. From Figure 1 it is evident that increased exposure to PV was associated with a graded increase in symptom severity on each DTS sub-scale (Re-experiencing, Avoidance, and Arousal) and on full-scale scores.

Finally, a series of multiple logistic regression analyses were conducted in order to explore the incremental validity of considering poly-victimization as a risk factor for PTSD, with two models being tested. In Model 1, the impact of different types of traumatic exposure on PTSD outcomes was explored after controlling for the effects of demographic variables (age, gender, grade, ethnicity, SES, and family structure).These analyses (Table 3 ) indicated that, with the notable exception of exposure to community violence, all types of victimization assessed by the DTI were significantly predictive of PTSD.

The analysis for Model 2 was identical to that for Model 1 except for the fact that PV was added as an additional predictor variable. Findings for Model 2 (Table 3) indicated that: (a) PV accounted for a significant proportion of the explained variance in PTSD outcomes across all types of victimization, (b) when PV was taken into account it greatly reduced or eliminated the relationship between type of victimization and PTSD, and (c) when compared to type of abuse, PV posed a greater risk for PTSD across all types of victimization excepting for emotional abuse, rape, and neglect.

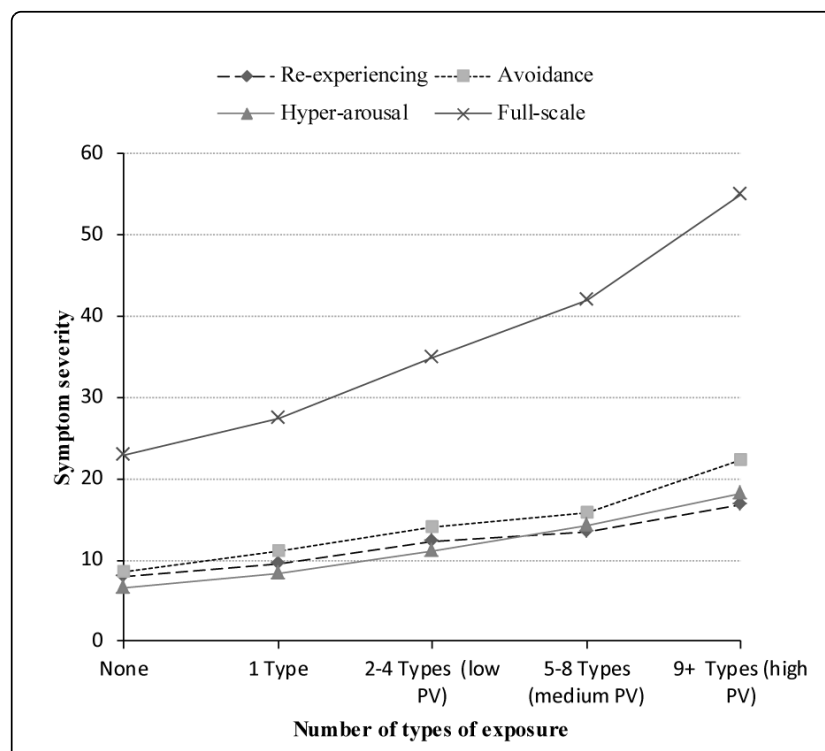

Figure 1: Symptom severity on the Davidson Trauma Scales by extent of exposure to poly-victimization $(n=719)$

\begin{tabular}{|l|l|l|l|}
\hline & $\begin{array}{l}\text { Model 1: } \\
\text { type of exposure }\end{array}$ & $\begin{array}{l}\text { Model 2: } \\
\text { type of exposure } \\
+\mathrm{PV}\end{array}$ & \\
\hline & Type & Type & $\mathrm{PV}$ \\
\hline $\begin{array}{l}\text { Any emotional } \\
\text { abuse }\end{array}$ & $2.91^{* *}$ & $2.25^{* *}$ & $1.84^{* *}$ \\
\hline Any rape & $2.82^{* *}$ & $2.35^{\star *}$ & $2.24^{\star *}$ \\
\hline Any neglect & $2.52^{* *}$ & $1.83^{* *}$ & $2.07^{* *}$ \\
\hline $\begin{array}{l}\text { Any witnessing } \\
\text { (domestic) }\end{array}$ & $2.12^{* *}$ & $1.68^{*}$ & $2.01^{* *}$ \\
\hline $\begin{array}{l}\text { Any domestic } \\
\text { assault }\end{array}$ & $1.99^{* *}$ & 1.43 & $2.02^{* *}$ \\
\hline $\begin{array}{l}\text { Any domestic } \\
\text { injury }\end{array}$ & $1.75^{*}$ & 1.56 & $2.29^{* *}$ \\
\hline $\begin{array}{l}\text { Any witnessing } \\
\text { (community) }\end{array}$ & $1.60^{*}$ & 1.10 & $2.48^{* *}$ \\
\hline Any molestation & 1.32 & 1.12 & $2.34^{\star *}$ \\
\hline $\begin{array}{l}\text { Any community } \\
\text { assault }\end{array}$ & 1.32 & 1.05 & $2.53^{* *}$ \\
\hline
\end{tabular}

Table 3: Type of exposure and poly-victimization as risk factors for PTSD, Note.n $=719$. PV = poly-victimization. All analyses controlled for age, gender, grade, ethnicity, SES, and family structure. ${ }^{*} \mathrm{p}<$. 05. ${ }^{* *} \mathrm{p}<.01$. 


\section{Discussion}

Prevalence rates for victimization observed in the present study are consistent with the view that South African children face a high risk of exposure to victimization. Nine out of 10 respondents (90\%) reported some form of lifetime victimization with $90 \%$ of victimized respondents reporting exposure to multiple forms of victimization. The median number of exposures was 5 , which is almost double the median of 2.6 reported for national samples of children in the United States [12].

With respect to risk factors for $\mathrm{PV}$, the present findings suggest that some children are more likely to become poly-victims than others, with the presence of poverty in the home emerging as one of the strongest predictors of PV. This finding is consistent with, and extends, the view that poverty constitutes a risk factor for traumatic exposure $[26,27]$, with the extension lying in the finding that poverty is also strongly associated with the risk of PV. In the present study, the extent of PV was also significantly, and positively, predicted by respondent's age and grade level, a finding which possibly reflects a combination of high multi collinearity between the two variables and increased opportunity for lifetime exposure to PV among older respondents.

Exposure to PV also varied as a function of exposure to specific types of victimization with some forms of victimization (sexual abuse, neglect, emotional abuse, and intentional physical injury) having more than $80 \%$ of their members in the high risk PV (5+ types) category. A common feature of these high risk forms of exposure is that they all involve direct exposure (as opposed to witnessing) of forms of victimization that occur predominantly in the home, suggesting that the extent of $\mathrm{PV}$ is related to both the locus (domestic versus community) and mode (direct versus vicarious exposure) of victimization types [2].

Consistent with findings from previous research $[9,10]$, the present findings indicate that exposure to high levels of PV (5+ types) more than doubled the risk for PTSD, with the extent of PV exposure being associated with a graded increase in the severity of PTSD symptoms across all symptom categories (Re-experiencing, Avoidance, and Hyper-arousal, and full-scale scores). These results are strikingly similar to findings obtained for lifetime exposure to PV in previous studies [12], which suggest a linear, no-threshold, dose-relationship between PV and adverse mental health outcomes (i.e., greater exposure to PV corresponding to increased adverse outcomes, with there being no evident threshold to this relationship).

Findings regarding the incremental validity of considering PV as a risk factor for PTSD are consistent with previous findings in indicating that PV accounts for a significant proportion of the variance in PTSD outcomes across all forms of victimization considered in the study [9-11], and that when PV was taken into account it greatly reduced or eliminated the relationship between type of victimization and PTSD [6].Taken together these findings suggest that (a) studies of the impact of victimization which focus on only a narrow range of victimization experiences may overestimate the association between such forms of victimization and traumatic outcomes, and (b) that practitioners working with traumatized children need to assess for a history of PV in order to identify children who are at greater risk for experiencing more extreme posttraumatic reactions.

\section{Conclusion}

The present findings indicate that the concept of PV has heuristic value in a developing country such as South Africa. High levels of PV observed in the present study suggest that future research and practice on childhood victimization would benefit from a more holistic approach to the assessment and conceptualization of child victimization which more adequately acknowledges, and addresses, children's full victimization profiles. From the perspective of clinical intervention, such a broader perspective could be used to not only triage traumatized children in terms of the likelihood of potentially adverse outcomes but also to inform targeted interventions designed to comprehensively address the full range of victimization experiences.

At the level of research, the concept of PV would appear to hold promise as a heuristic tool for providing a more comprehensive understanding of the extent, nature, and impact of child victimization in the South African context. Findings obtained in the present study, are remarkably similar to findings obtained from samples of children in the United States $[6,12]$, suggesting that PV is a rigorous construct which is likely to be relevant to our understanding of posttraumatic symptomatology among victimized children in developing countries. As such, further research would appear to be strongly indicated in order to not only replicate the present findings but also to extend the present findings using more representative samples drawn from the South African population.

Finally, several limitations need to be acknowledged in interpreting these findings. First, the present findings were obtained from an urban sample of school-going adolescents in one particular school district, and may not generalize to adolescents in other districts, or to samples of out-of-school youth in South Africa. Second, the cross-sectional nature of the present research would caution against any strong causal inferences. And third, a reliance on self-reports of lifetime victimizations likely to have led to some degree of recall bias.

\section{Acknowledgement}

This work is based upon research supported by the South African National Research Foundation (NRF).Any opinion, findings and conclusions or recommendations expressed in this material are those of the authors and therefore the NRF do not accept any liability in regard thereto.

\section{References}

1. Kendall-Tackett KA, Williams LM, Finkelhor D (1993) Impact of sexual abuse on children: A review and synthesis of recent empirical findings. Psychol Bull 113: 164-180.

2. Horn JL, Trickett PK (1998) Community violence and child development: A review of research. In: Trickett PK, Schellenbach C, eds, Violence against Children in the Family and Community. Washington, DC: American Psychological Association 103-138.

3. Nansel T, Craig W, Overpeck M, Saluja G, Ruan J (2004) Health Behavior in School-Aged Children Bullying Analysis Working Group. Crossnational consistency in the relationship between bullying behaviors and psychosocial adjustment. Arch Pediatr Adolesc Med 158: 730-736.

4. Abrahams N, Jewkes R (2005) what is the impact of witnessing mother abuse during childhood on South African men's violence as adults? Am J Public Health 95: 1811-1816.

5. Dong M, AndaRF, Filitti VJ, Dube SR, Williamson DF, et al. (2004) The interrelatedness of multiple forms of childhood abuse, neglect, and household dysfunction. Child AbuseNeglect 28: 771-784. 
Citation: Collings SJ, Penning SL, Valjee SR (2014) Lifetime Poly-Victimization and Posttraumatic Stress Disorder among School-Going

6. Finkelhor D, Ormrod RK, Turner HA (2007) Poly-victimisation: A neglected component in child victimisation. Child Abuse Neglect 31: 7-26.

7. Saunders BE (2003) Understanding children exposed to violence: Toward an integration of overlapping fields. Journal Interpers Violence 18 356-376.

8. Turner HA, Finkelhor D, Ormrod R (2010) Poly-victimisation in a national sample of children and youth. Am J Prev Med 38: 323-320.

9. Ford JD, Elhai JD, Conner DF, Freuh BC (2010) Poly-victimisation and risk of posttraumatic, depressive, and substance use disorders and involvement in delinquency in a national sample of adolescents. J Adolescent Health 46: 545-552.

10. Naar-King S, Silvern L, Ryan V, Sebring D (2002) Type and severity of abuse as predictors of psychiatric symptoms in adolescence. JFam Violence 17: 133-149.

11. Holt MK, Finkelhor D, Kantor MK (2007) multiple victimisation experiences of urban elementary school students: Associations with psychosocial functioning and academic performance. Child Abuse Neglect 31: 503-515.

12. Finkelhor D, Ormrod RK, Turner HA (2009) Lifetime assessment of poly-victimisation in a national sample of children and youth. Child Abuse Neglect 33: 403-411.

13. Raskauskas J (2019) Multiple peer victimisation among elementary school students: Relations with social-emotional problems. Social Psychology of Education: An International Journal 13: 523-539.

14. Richmond JM, Elliott AN, Pierce TW, Aspelmeier JE, Alexander AA (2009) Polyvictimisation, childhood victimisation, and psychological distress in college women. Child Maltreatment 14: 127-147.

15. FinkelhorD, Ormrod RK, Turner HA (2007) Re-victimisation patterns in a national longitudinal sample of children and youth. Child Abuse Neglect 31: 479-502.

16. Finkelhor D, Ormrod RK, Turner HA, Hamby SL (2005) Measuring poly-victimisation using the Juvenile Victimisation Questionnaire. Child Abuse Neglect 29: 1297-1312.
17. Barbarin OA, Richter L, deWet T (2001) Exposure to violence, coping resources, and psychological adjustment of South African children. Am J Orthopsychiat 71:16-25.

18. Mc Cormack A (2010) a study of the extent and nature of polyvictimisation of adolescents in Heideveld. Unpublished master's dissertation, University of South Africa, Pretoria, South Africa.

19. Seedat S, Nymai C, Njenga FM, Vythilingum B, Stein DJ (2004) Trauma exposure and post-traumatic stress symptoms in urban African schools. Brit J Psychiat 184: 169-175.

20. Shields N, Nadasen K, Pierce L (2008) the effects of community violence on children in Cape Town, South Africa. Child Abuse Neglect 32: 589-560.

21. Shields N, Nadasen K, Pierce L (2009) A comparison of the effects of witnessing community violence and direct victimisation among children in Cape Town, South Africa. J Interpers Violence 24: 1192-1221.

22. Ward CL, Flisher AJ, Zissis M, Muller M, Lombard C (2001) Exposure to violence and its relationship to psychopathology in adolescents. Injury Prevention 7: 297-301.

23. Finkelhor D, Hamby SL, Ormrod RK, Turner HA (2005) The JVQ: Reliability, validity, and national norms. Child Abuse Neglect 29: 383-412.

24. Collings SJ, Valjee SR, Penning SL (2013) Development and preliminary validation of a screen for interpersonal childhood trauma experiences among school-going youth in Durban, South Africa. Journal of Child and Adolescent Mental Health 25: 23-34.

25. Davidson J (2003) Davidson Trauma Scales (DTS). North Tonawanda, NY: Multi-Health Systems.

26. Seedat M, Van Niekerk A, Jewkes R, Suffla S, Ratele K (2009) Violence and injuries in South Africa: Prioritising an agenda for prevention. Lancet 374: 1011-1022.

27. Townsend L, Dawes A (2004) Individual and contextual factors associated with the sexual abuse of children under 12: A review of recent literature. In: Richter L, Dawes A, Higson-Smith C, eds, Sexual Abuse of Young Children in South Africa. Cape Town: HSRC Press 55-94. 